\title{
Rab Ne Bana Di Jodi and A Little Things Called Love in Kristeva's Intertextuality
}

\author{
Kudsiyah $^{1}$, Lusia Kristiasih Dwi Purnomosasi ${ }^{2}$ \\ Universitas PGRI Madiun, Indonesia \\ qudsiyahfharadisa757@gmail.com ${ }^{1}, \underline{\text { lusiakdp@unipma.ac.id }}$
}

\begin{abstract}
The aim of this research is analyzing the phenotext, the genotext and finding the reason the symbol of culture which significance in modern era. Theory of intertextuality and semiotic are displayed to help this research. Phenotext and genotex are the part of intertextuality used in this research. Phenotext is a pattern which can be linked to the communication from subject to addressee. To find the data the researcher needs to choose what kinds of utterances in verbal form from the scene of both movies. The utterances can be find how the main character (subject) is faced with their pairs (addressee). In genotext, genotext is in a text points out the transfer from drive energy (body movement) includes the intonation or rhythm. The researcher can find how the main character articulates the structure which correlates with the physic structure such as body movement that belongs to symbolization of feeling expression and act. The data is taken from the scenes of Rab Ne Bana Di Jodi and A Little Things Called Love movies. The instrument of data is documentation The results of the study; in phenotext there are some dialogues used by the main character in verbal form, in genotext there are some visuals formula romance of in expressing the feeling with physic structure of both movies, and symbol of culture used by the main characters becomes the way of western for changing the mindset of Asian to follow their culture.
\end{abstract}

Keywords: intertextuality; phenotext; genotext

\section{INTRODUCTION}

Nowdays, Bollywood is classified as the biggest movie industry in the world in terms of amount of people employed and number of films produced. Not only Bollywood but also Thailand movie is one of movie that exist in this era. Therefore in this study takes one Bollywood movie and one Thailand movie. Those are Rab Ne Bana Di Jodi (Bollywood) and A Little Things Called Love (Thailand). Rab Ne Bana Di Jodi won three awards and got eleven nominations. Meanwhile A Little Things Called Love won an award and got two nominations. The researcher choose those movies because the resercher sees that both of them shows a same phenomenon, and like a same plot story.

Those movies have the same event to love someone and to wrest someone who loved by changing the appearance and helped by used things or symbol that can changed their new appearance. From that the researcher sees if that phenomenon can be intertextuality for to do the research. Intertextuality study is the study of aligned texts which have a relationship in some elements both two texts. To see how keep their relation, it will fit to use Kristeva's intertextuality. Kristeva introduces two new terms in intertextuality are the phenotext and the genotext.

Kristeva introduces two new terms the phenotext and the genotext Kristeva in Allen (2000: 50). The phenotext is that part of the text bound up with the language of communication, the theticthesis, which displays definable structure and appears to present the voice of a singular, unified subject. The genotext is that part of the text which stems from the 'drive energy' emanating from the unconscious and which is recognizable in terms of 'phonematic devices' such as rhythm and intonation, melody, repetition and even kinds of narrative arrangement.

In this research the researcher uses theory of as Semiotics to identify the symbol in Rab $\mathrm{Ne}$ Bana Di Jodi and A Little Things Called Love. In reason, the researcher needs to culture symbolyzed in those movies. In this research, the classification of object, especially symbol is the possible for the 
researcher uses. Peirce writes that a symbol is a sign that refers to its object, which it denotes by virtue of a law. Peirce clarifies this by stating that the law is an association of common ideas.

By using theory of intertextuality and semiotic, this research aims to analyze the phenotext, the genotext and find the reason why the symbol of culture significance in modern era. This research focuses on the intertextuality study in the Rab Ne Bana Di Jodi and A Little Things Called Love which have a symbol of culture that used as tool in modern era.

\section{METHOD}

This research takes two types of data; they are primary and secondary data. In primary data the data are the movies: Rab Ne Bana Di Jodi and A Little Things Called Love. The secondary data sources are taken from books, article, journal, thesis, disertation which discuss the same object in intertextuality. They are used to support the research in answering the problem. This research is conducted by qualitative data which is based on content analysis technique.

\section{RESULT}

1) Phenotext

The researcher presents the dialog of the main character which is related with enthusiasm of main character in those movies. In enthusiasm here, the researcher finds the way of the main character to wrest someone who loved by changed their new appearance, the way of the main character attracting and following the activity someone they loved.

\section{Rab Ne Bana Di Jodi}

Frame 1:00:38:40

Surinder :"I want her to fall in love with me. Make her fall in love with me my friend. Do something that makes me the hero of her life. The kind of hero that she loves to watch in film and then she will come in my arms. Do some magic with your hands and make my love story my friend" Bobby :"Balwinder viz. Bobby Khosla started this salon for this day perhaps. Now you wait and watch how I write your love story".

\section{A Little Things Called Love}

Frame 2: 00:32:03

Gie : "Tip no 7 is from Gypsies, let love inspire you. The power of love shall make you smarter, prettier and better in every way. Then that person will finally notice you".

Nam : "Hey what?"

(Nam's friend do the treatment to Nam)

Frame 1 and frame 2 show similarities phenomenon from the main character. Those frames tell how enthusiasm the main character for changing their appearances to get attention from the people she wants. Frame 1 shows that Surinder asks his best friend to do something that makes a hero comes in to Taani's life. Frame 2 shows that Nam's friends help and do the treatment for Nam. Frame 1 and frame 2 show the way of the main character changed appearance by their friends. Frame 1 and frame 2 have the equal purpose after getting new appearance, they want people they loved respect their love too.

Rab Ne Bana Di Jodi

A Little Things Called Love

\begin{tabular}{|ll|}
\hline Frame 3: 00:47:29 & Frame 4: 00:40:33 \\
& Nam : "We meant to tell you......." \\
Bobby :"I just don't get it. You said & Cheer : "We meant to dance... \\
\hline
\end{tabular}

English Teaching Journal: A journal of English Literature, Linguistics, and Education 31 | 


\begin{abstract}
you will watch Taani dance and then go home and surprise her,......".

Surrinder :"Oh you fool! I have got the chance to dance with Taani everyday and you want me to loose that. Do you think if she knew it was me, would she ever dance with a geek like me? Never, and even if she did she wouldn't be the same Taani I saw today.
\end{abstract}

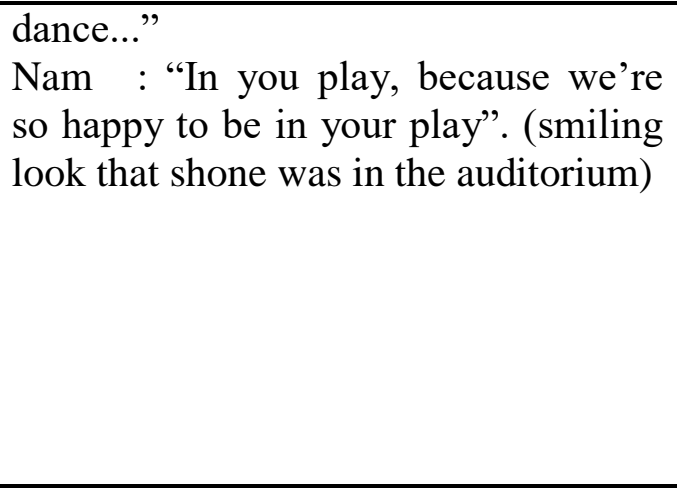

Frame 3 and frame 4 show that the main character follows the activity of someone they loved to attract that people. Frame 3 shows that Surrinder comes to the dance club as Raj, although Surrinder cannot dance he is willing dancing to attract Taani. Frame 4 also shows that Nam wants to join drama club. It is only for Shone which is in the auditorium, Nam is not interested to follow the drama club before.

2) Genotext

In collecting the data, the researcher sees every formula which is happened in those movies until the event becomes the basic to analyze of genotext in the visual representation of both movies. In analyzing the genotext, based on the formula romance exist on Ida. In her book, Ida (39:2010) explains that Radway found the narrative structure of popular romance in more detail. According to her there are 13 structures in a romance story. Some of the formulas or structures are taken by the researcher to analyze the genotext of both movies. One of the formulas explained that the heroine interprents the hero's behavior as evident of sexual interest.

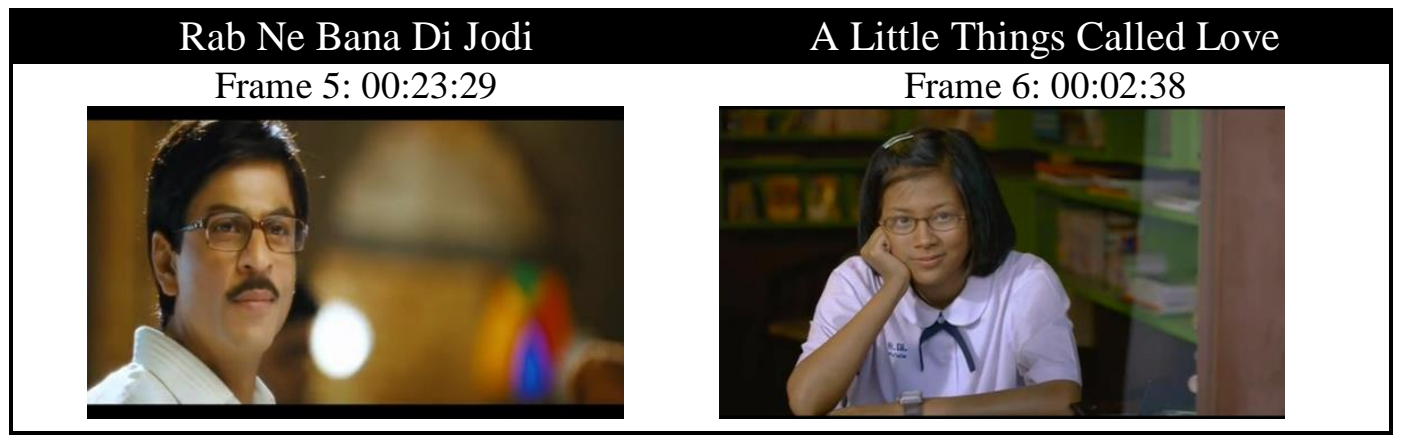

Frame 5 and frame 6 show similarities phenomenon from the main character. These figures show the expression of the main character. From these pictures the main character are in happiness expression. From the face of the main character shows how they appreciate the people whom they loved by smiling. The main character feels amazed by what their loved do. They think that the person they love is the right person they choose. They are very proud and amazed by the nature of their loved ones.

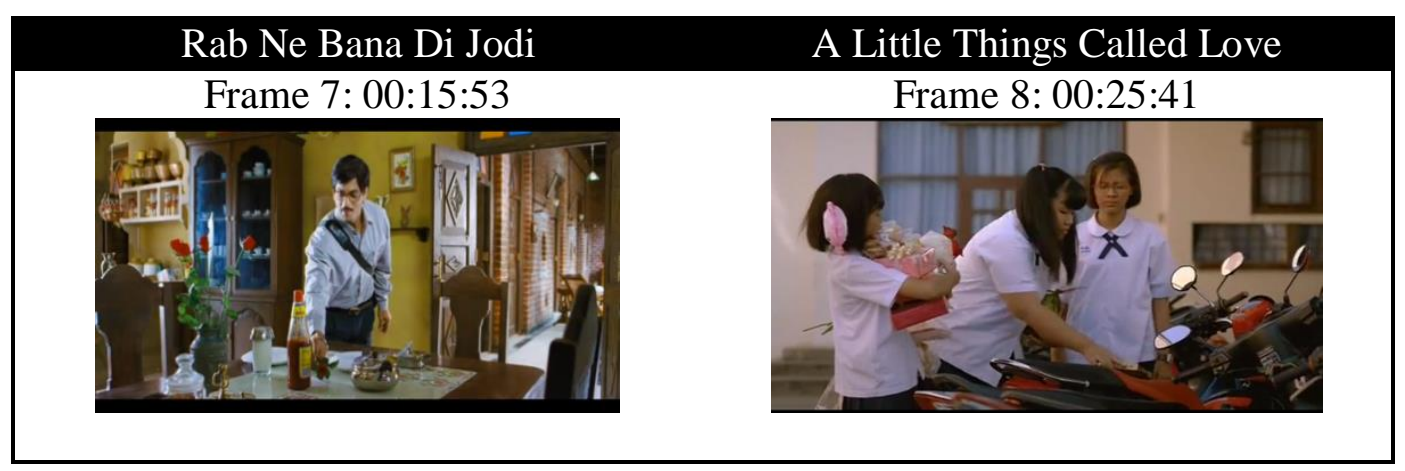

32 | English Teaching Journal: A journal of English Literature, Linguistics, and Education 
From the frame 7 and frame 8 are expressing their secret love. The main characters give a gift to someone whom they loved. That expression is one of their effort to attract someone. The effort of the main character is giving something to surprise by well planned. They hope that what they do will attract the attention of their loved ones.

3) Symbol of culture

The researcher presents the picture from both movies related with symbol cultures that used as tool in this modern era for change the appearance. Then, the researcher finds the reason why the tools as symbol of culture become a significance in this modern era.

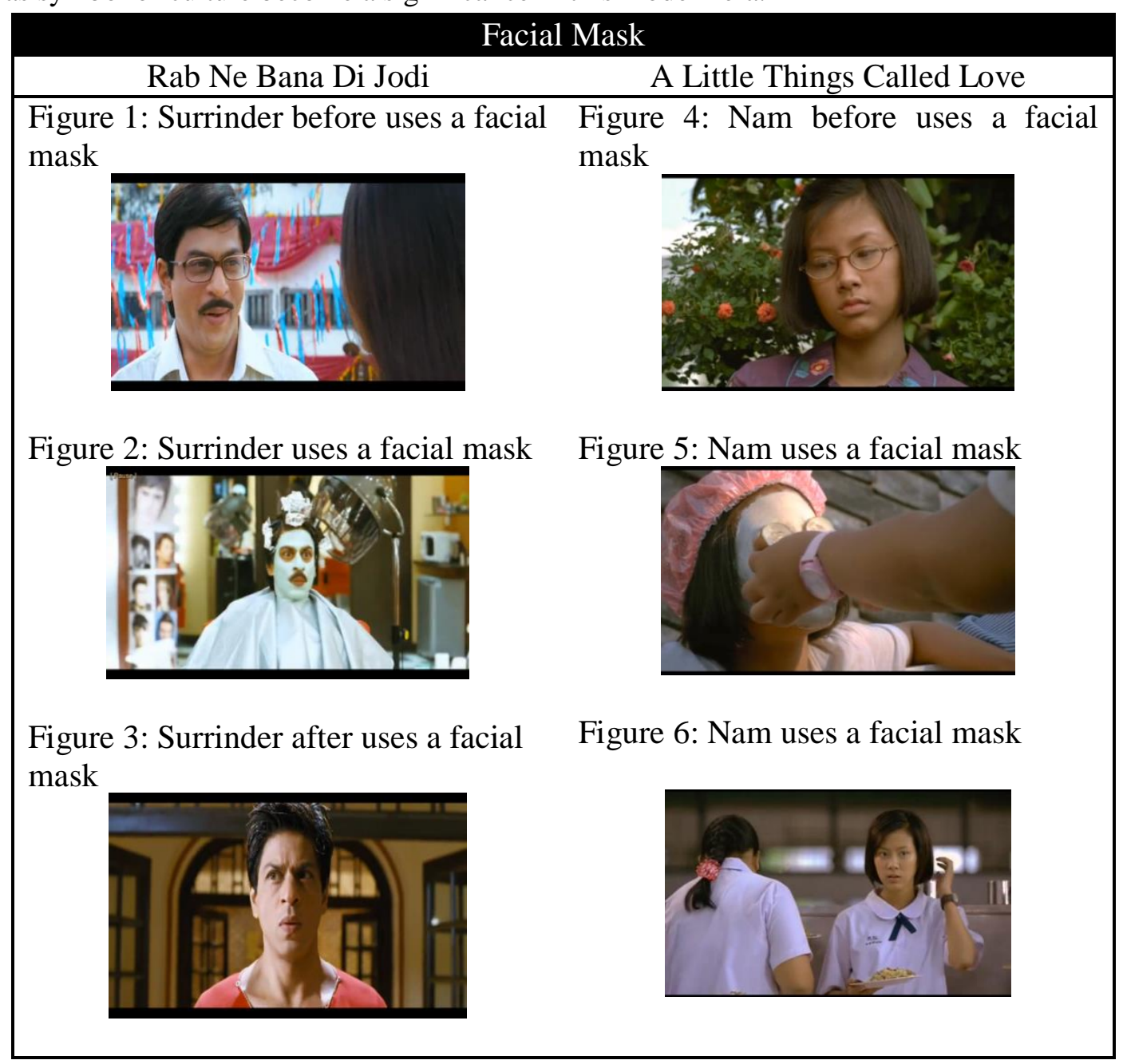

From those pictures, in figure 3 and frame 6 the main character from Rab Ne Bana Di Jodi and A Little Things Called Love used a facial mask as a tool to whiten skin. Both are very enthusiastic to do the treatment, especially in wearing a facial mask. The two main characters are dark skinned, therefore a facial mask can brighten and whiten the skin of the main characters.

Facial mask is a kind of skin care product that can apply on face. It is considered as one of the easiest ways to get healthy and supple skin within a few minutes. In this modern era the use of facial masks has become common for women and men. The appearance becomes the main factor why facial mask becomes one way to keep the appearance to keep looking attractive, beauty, or ageless.

Facial mask is popular in India, as the primary data in figure 3.2. The following show India composis the ingredients of facial mask. It uses a turmeric. Based on Turmeric World (Aaditya: 2009), India is the largest producer, consumer and exporter of turmeric in the world. Indian turmeric is considered to be the best in the world market because of its high curcumin content. India accounts for about 80 per cent of world turmeric production and 60 per cent of world exports. Asian countries

English Teaching Journal: A journal of English Literature, Linguistics, and Education 33 | 


\section{English Teaching Journal, Vol. 5 No. 1, Juni 2017}

ISSN: 2338-2678

consume much of their turmeric production. In Thailand and India itself they usually use a mask of spices such as turmeric.

The big benefit that appears in figure 3 and 6 is making both main characters face become brighten than before as in figure 1 and figure 4 . As each origin skin colour is brown skin, but people in Asia especially India and Thailand want to have a fairy skin as like people in Western. Based on Prasad and Unnikrishnan (2016), India has been influenced significantly by foreign cultural due to foreign rulers, interactions through trade and other cultural exchanges. As a result of these influences, the concept of beauty in India has become intertwined with fairness of the skin colour. Recently, since the economic reforms which started in 1992, globalization has started to influence Indian sociocultural life via increased influx of foreign ideas through various media, increased business and trade with other parts of the world without any barriers etc. Because of the upsurge in the Western influence on India, the various Media spaces are filled with the Western pop stars, actors, models etc. From that the researcher sees that there are many impacts of beauty in India from western.

The similar matter happens in Thailand. Through the cooperation among countries in Asia and global, Thailand gets the effect of a beauty concept. As quoted from Mikva (2014), Thailand is one of country that were never colonized. Thailand it was never formally colonized by a European state, but it still expresses a desire to follow a number of aesthetic ideals that could be considered to be western. the researher also finds in article comes from Napat Chaipraditkul entitled Thailand: beauty and globalized self-identity through cosmetic therapy and skin lightening. 2013. In that article author tell influences of Indian thought systems are evident across all of South East Asia. Indian caste systems and myths, the ideal of whiteness played a role in Asian society in subtle forms even before European colonization of Africa, Asia and the world. The idealization of the perfect marriage and fair skin is buried deeply in the minds of Asian women. Fair skin is believed to symbolize youthfulness and high quality in women. In Thailand, fair skin symbolizes health and wealth. From that article the researcher sees that although Thailand never colonized but concept of beauty in Thailand still influence by Asian. Asian itself there are a country that have colonized therefore western culture entered to the Asia. Facial mask is one simple way for women or man to look their skin brighter and white or to maintain or care for their facial skin.

\section{DISCUSSION}

For genotext the researcher has found some equations of expression and act by the main character of both film. One such resemblance is from how they look with the full of admiration contained in frame 5: 00:23:29 and on frame 6:00:2:38. The difference is only in terms of age that makes the main character in Rab Ne Bana Di Jodi more deeply in the expression. The differences appear from both main characters, Surrinder and Nam. The expression used by Nam as a younger girl is not same with Surrinder as the older character. Viewed in terms of age Nam as a younger girls a student who is still sitting in junior high school is when expressing his feelings he is more open and openly admitted to the person he loves. While Surrinder as a old man and he is a office worker, he is more able to control the emotions he has even he can hide his feelings. He does not openly express his feelings with words but rather expresses his feelings with the treatment even though it is secretly all at once. Viewed from the side of sex also looks different how to express both women and men. Both movies have gender differences from the main player, Surrinder in Rab Ne Bana Di Jodi he is old man and Nam in A Little Things Called Love is a younger girl. As described in the journal comes from Heather, Urry, and Gross, on the titled "Emotion Regulation in Older Age", in 2010. It it said that the older adults are better at predicting feelings of emotional arousal than younger adults (Nielsen, Knutson, \& Carstensen, 2008). Linked to the journal, Surrinder deeply shows his expression to the

\section{4 | English Teaching Journal: A journal of English Literature, Linguistics, and Education}


woman but in different character. He knows how to hide his feeling covered by the other character he played. In other hand, Nam as a higher school student is more expressive in her feeling. She does not play another character to hide her feeling. She only shows the nature of herself in front of her boy she admires.

The phenotext itself researcher have found some similarities in dialogue that reveal how such a major or main character enthusiasts to change their appearance. Researcher assumes that the two main characters have similarities with the help of their closest friends can change his appearance. The researcher found the research journals that have a relationship with this research. The journal by Ogunpitan S. A from Lagos State University in 2007 entitled "Genotext and intertext: The grammatology of a literary idiolect". In the journal the author analyzed genotext and phenotext from the process of reading to extract or to discover meaning from a text. The researcher said that novel not just novel, but a Nigerian novel. It distintictive Nigerian qualities in setting, characterization, and most evident of all, the language that represents the spoken dialect of Nigeria. From Rab Ne Bana Di $J o d i$ as the story of Indian man, Surrinder. The researcher finds some dialogues of his way to run his intention of getting attention from the woman he loved. By his friend, Bobby who has helped Surrinder in changing his appearance while in the movie A Little Things Called Love, there are some friends who helped Nam. The obvious difference from the two movies is that the main character of $A$ Little Things Called Love wants to win the heart of someone who is popular student of the school. For Rab Ne Bana Di Jodi the main character wants to win his wife's heart, Taani who does not like the wedding. Another difference is in the number of friends who help the main character in changing their appearance. Another difference is the movie A Little Things Called Love in winning a person's heart they have a reference that is the book they read about advice of the guidebook recipes of love which refers to the main character Nam to change his appearance. In the movie Rab Ne Bana Di Jodi main character namely Surrinder, after watching the movie with his wife, Surrinder assumes that the actor in that movie is someone who wants his wife. Even some differences above, the researcher finds the relate element of phenotext appear from the dialogues among main characters with each friend.

The symbol of modern era represented in the movies is the effect of globalization. Western influences the countries in Asia especially India and Thailand. The way of influencing comes from various surface. One of ways to influence uses media. Media leads people around the world follow the modernity. "The media has proved to be a powerful source when it comes to how women view themselves since many magazines, newspapers and television programs are geared towards portraying the ideal woman from her expected roles to how she should look" as quoted from Portia Tshegofatso Loeto entitled Notions of Beauty and Attractiveness (2014). Today western culture still focuses on perfection, but the idea of what is perfect has shifted. Today, a thicker figure is no longer seen as the standard of beautiful, but instead extremely slender is what is sought after. Being skinny is advocated by the fashion industry, by television, internet, and every other form of media available. Thailand has never been formally colonized by European nation. However, the tendency can be observed that in particular Thai women generally strive for aesthetic ideals which can be considered Western. The most prominent beauty image is that of considering fair skin to be more desirable than dark skin. The main character from A Little Things Called Love and Rab Ne Bana Di Jodi itself also change skin from dark skin to fair skin or white skin to looks beauty for attract someone they loved. British colonialism reinforced the hierarchy of the Indian caste system, and often equated higher castes and higher power status to lighter skin.

\section{CONCLUSION}




\section{ISSN: 2338-2678}

Based on the result and discussion of this research, the researcher concludes that The researcer assumes that symbol of culture here is the object or the atribute of main character become a significance in this modern era, such as facial mask in change the appearance to looks perfect like western style. The changing appearance leads the characters transform to be modern as the effect of globalizationin phenotext, the researcher classifies the utterances used by the main character in verbal form from the scene of both movies. The utterances can find how the main character is faced with their pairs. It is begun before the main character is changing their appearances and after they have changed. For genotext, the researcher claasifies genotext in the visual representation of both movies. It is taken from how the way of main character expressing their feeling with physic structure. So phenotext and genotext is the way of the researcher finding the similar verbals and visuals representation.

\section{REFERENCES}

Adi, I. R. (2011). Fiksi Populer (Teori dan Metode Kajian).Jogjakarta: Pustaka Pelajar.

Allen, G. (2000). Intertextuality. London: Routledge. Retrieved from: http://docs.lib.purdue.edu/clcweb/vol10/iss3/1.

Kothari, C. R. (2004). Research Methodology: Method and Techniques. New Delhi: New Age International (P) Ltd.

Kristeva, J (Author), Waller, M., \& Roudiez, L. S., (Translator). Revolution in Poetic Language. New York: Columbia University Press.

Kristeva, J. (Author), Roudiez, L. S., \& Jardine, A., (Eds). Gora, T. (Translator). A Semiotic Approach to Literature and Art, New York: Columbia University Press

Ogunpitan, S. A. (2007). Genotext and Intertext: The Grammatology of a Literary Idiolect. Lagos State University.

Short, T. L. 2007. Peirce's Theory of Sign, New York: Cambridge University Press. 